
\title{
$\angle S$ Research Square \\ Requirement for containing etoposide in the initial treatment of lymphoma associated hemophagocytic lymphohistiocytosis
}

\section{Yue Song}

Capital Medical University Affiliated Beijing Friendship Hospital

\section{Jingshi Wang}

Capital Medical University Affiliated Beijing Friendship Hospital

\section{Yini Wang}

Capital Medical University Affiliated Beijing Friendship Hospital

\section{Lin Wu}

Capital Medical University Affiliated Beijing Friendship Hospital

Zhao Wang ( $\nabla$ wangzhao@ccmu.edu.cn )

Capital Medical University Affiliated Beijing Friendship Hospital

\section{Research article}

Keywords: hemophagocytic lymphohistiocytosis, lymphoma, etoposide, treatment, prognosis, Epstein-barr virus

Posted Date: November 9th, 2020

DOI: https://doi.org/10.21203/rs.3.rs-40791/v2

License: (c) (1) This work is licensed under a Creative Commons Attribution 4.0 International License. Read Full License

Version of Record: A version of this preprint was published at Cancer Biology \& Therapy on November 1st, 2021. See the published version at https://doi.org/10.1080/15384047.2021.1996139. 


\section{Abstract}

Background: Hemophagocytic lymphohistiocytosis $(\mathrm{HLH})$ is a severe or even fatal inflammatory status caused by a hereditary or acquired immunoregulatory abnormality. Lymphoma associated hemophagocytic lymphohistiocytosis (LAHS) is a kind of secondary HLH (sHLH). It has the worst prognosis among sHLH. However, there's still no standard treatment strategy. The argument mainly focuses on whether an HLH-directed or malignancy-directed approach should initially be adopted. Etoposide is one of the key drugs in HLH treatment, also effective in lymphomas. We sought to identify the importance of containing etoposide in initial treatment, comparing with the chemotherapy which directed at lymphoma but without etoposide.

Methods: 66 patients diagnosed as LAHS in our center between Jan 12015 and Dec 312017 were divided into two groups according to weather the initial treatment containing etoposide, or other lymphomadirected chemotherapy without etoposide.

Results: The remission rate of the initial etoposide group (52 patients) is significantly better than that of no initial etoposide group (14 patients) $(73.1 \%$ vs. $42.9 \%, p=0.033)$. The 2 -month survival rate $(79.8 \%$ vs. $46.8 \%, p=0.035$ ) and overall survival (median survival time $25.8 w$ vs. $7.8 w, p=0.048$ ) of the initial etoposide contained group is significantly better. Multivariate cox analysis revealed that for patients without EBV infection (37 cases), initial treatment with etoposide could significantly improve prognosis $(p=0.010$, $\operatorname{Exp}(B)=0.183)$, but for patients with positive EBV, it's not significant.

Conclusions: Containing etoposide is beneficial in the initial treatment of LAHS, weather using the HLH directed or lymphoma directed strategy. It provides higher response rate, lower mortality rate and better survival, especially for EBV negative patients.

\section{Background}

Hemophagocytic lymphohistiocytosis $(\mathrm{HLH})$ is a severe or even fatal inflammatory status caused by a hereditary or acquired immunoregulatory abnormality[1-3]. It is divided into two categories: primary and secondary. Secondary HLH (sHLH) is often associated with and caused by infections, malignant tumors, and autoimmune diseases. Malignancy $\mathrm{HLH}(\mathrm{M}-\mathrm{HLH})$ is a kind of $\mathrm{sHLH}$, and lymphoma associated (LAHS) is the most common kind of M-HLH. M-HLH suffers the worst prognosis in secondary HLH[4], which has a high early mortality and the median survival is considered to be less than 2 months[5]. That is because that the treatment of LAHS is often faced with many difficulties, such as HLH controlling problem, the high recurrence rate, the lymphoma is hard to relieve, and so on. However, there's still no standard strategy for LAHS's treatment up until now. There are no universal conclusions on whether an HLH directed, malignancy-directed or combined approach should initially be adopted[6]. In the study of adult M-HLH by Gevorg Tamamyan in 2016, they noted a very aggressive and rapid progression of HLH with M-HLH, with a majority of patients dying from HLH within 2-4 weeks in spite of continued treatment of the underlying malignancy[5]. In the consensus review on malignancy-HLH in adults in 2017, it is suggested that once $\mathrm{HLH}$-triggered organ damage occurred, the application of lympholytic agents must be considered, including 
etoposide, corticosteroids, polyvalent immunoglobulins which targets the cytokine storm and T-cell proliferation, and DEP regimen as salvage therapy. Neoplastic specific treatment should be put after the organ function is re-established[6]. However, it is noted only as an expert opinion, prospective, randomized or controlled clinical trials is still needed to support. Etoposide is one of the key drugs in HLH treatment[7], and its importance and necessity, especially in initial treatment of some types of $\mathrm{HLH}$, are getting a lot attention. In previous report, the initial treatment with etoposide is believed to improve the prognosis of EBV-HLH patients, especially in adult patients $[8,9]$. In the Alison S. and Nancy B.'s experience of HLH treatment, they suggested that etoposide containing chemotherapy regimen in LAHS should be strongly considered[10]. Also, in 2018هCamille Bigenwald et al. reanalyzed 71 cases of LAHS and found out that etoposide contained is an independent factor in improving prognosis[11]. Beside of the controlling HLH cytokine storm, etoposide also has a certain anti-tumor effect, especially in lymphoma[12]. By comparing the etoposide-containing regimen and the lymphoma specialized chemotherapy without etoposide, sought to identify the importance of including etoposide in the initial treatment of LAHS. Can etoposide control $\mathrm{HLH}$ at an early stage and also play a certain anti-lymphoma effect, so that it may address the treatment of $\mathrm{HLH}$ and lymphoma at the same time? This may lay a foundation for the future better treatment strategy of LAHS.

\section{Methods}

\section{Patients}

534 patients diagnosed as HLH (according to HLH-2004 diagnostic criteria[7]) in our center between Jan 1, 2015 and Dec 31, 2017 were screened. Among the 534 patients, 80 were diagnosed with a hematological malignancy, and of these, 75 were determined to be lymphoma. The pathological criteria of the diagnosis of the lymphoma were according to the World Health Organization classification of lymphoid neoplasms. All pathological biopsies were reviewed double blinded by two pathologists. Six patients were excluded because of missing data. Three patients with HLH occurred during chemotherapeutic treatment referred to as Ch-HLH were excluded[6, 13]. Finally, 66 patients were included in the analysis. The medical records were reviewed by investigators and they were in responsible for selecting cases and collecting data? They have all been trained to collect clinical data.

According to the differences of initial treatment regimen, the patients were divided into two groups according to weather the initial treatment containing etoposide. There were 52 patients with initial etoposide and 14 without one. The treatment regimens contained initial etoposide include HLH-94/2004 regimen (20 cases), DEP (doxorubicin-etoposide-methylprednisolone) (17 cases), L-DEP (PEG-aspargase and DEP regimen) (8 cases), E-CHOP (etoposide, cyclophosphamide, hydroxydaunorubicin, vincristine, prednisone) (5 cases) and RE-CHOP (Rituximab and E-CHOP regimen) (2 cases); for those lymphomadirected chemotherapy but without etoposide, the regimens include CHOP/COP ( 5 cases), R-CHOP/COP (5 cases), L-GDP (2 cases), and P-Gemox (PEG-aspargase, Gemcitabine, Oxaliplatin) (2 cases). The dose of etoposide is $75-100 \mathrm{mg} / \mathrm{m} 2$ for HLH-94/2004 regimen, $100 \mathrm{mg} / \mathrm{m} 2$ for DEP/L-DEP regimen once a week $[14,16], 60-100 \mathrm{mg} / \mathrm{m} 2 \mathrm{~d} 1-\mathrm{d} 3$ for E-CHOP regimen. 
The positive EBV is defined as EBV-DNA copy number of peripheral blood $\geq 500 \mathrm{copies} / \mathrm{ml}$ (pass the EBV international standard, namely: NIBSC number 09/260 for detection[14]), or EBV-encoded small RNA $($ EBER)+ in tissues.

\section{Efficacy evaluation criteria and observed indicators}

Age, gender, pathological type of lymphoma, IPI (International prognostic index) scores, initial clinical symptoms as well as laboratory findings, initial treatment regimen, response rate, transplantation, and outcome of each patient.

As this study is mainly focusing on the HLH part of LAHS, so the assessment of the efficacy of LAHS followed the criteria proposed by Marsh et al and revised by Yini Wang et al $[15,16]$. A complete response (CR) was defined as the normalization of all quantifiable symptoms and laboratory markers of $\mathrm{HLH}$, including levels of soluble CD25, ferritin, and triglyceride; hemoglobin levels; neutrophil and platelet counts; and alanine aminotransferase (ALT) levels. A partial response (PR) was defined as improvement in two or more of the following quantifiable symptoms and laboratory markers by 2 weeks: 1.5 -fold decrease in soluble CD25 response; ferritin and triglyceride decreases of at least $25 \%$; an increase of at least $100 \%$ to $>0.5^{\star} 10^{9} / \mathrm{L}$ in patients with an initial neutrophil count of $<0.5^{\star} 10^{9} / \mathrm{L}$; an increase of at least $100 \%$ to $>2.0 * 10^{9} / \mathrm{L}$ in patients with an initial neutrophil count of 0.5 to $2.0^{*} 10^{9} / \mathrm{L}$; and a decrease of at least $50 \%$ in patients with initial ALT levels $>400 \mathrm{U} / \mathrm{L}$. Additionally, the subject's body temperature must have reverted to normal ranges for either CR or PR to be diagnosed. Failure to achieve PR was defined as no response.

Besides the clinical manifestation mentioned above and laboratory findings for efficacy evaluation, considering the main side effects of etoposide and lymphoma-directed chemotherapy, the level of myelosuppression was graded with the World Health Organization (WHO) Toxicity Grading Scale for Determining the Severity of Adverse Events[17].

\section{$\underline{\text { Survival and statistical analysis }}$}

Follow-up started at the date of LAHS diagnosis and ended at the date of death or last examination. Overall survival (OS) was calculated from the diagnosis of HLH to death of any cause. When the latter date was not reached, the date was censored at the time of the last follow-up evaluation. Cases who underwent allogeneic hematopoietic stem cell transplantation were censored on the date of transplantation.

SPSS 22.0 (IBM, New York/USA) statistical software was adopted, and data that did not fit a normal distribution are presented as median and range. T-test was used for data that fit a normal distribution and homogeneity of variance, and Wilcoxon rank sum test was used for others. Survival functions were estimated by Kaplan-Meier method. Confidence intervals were calculated using log-transformation for survival analysis. The log-rank test was used to compare survival between different groups. The Cox proportional hazards model was used in the multivariate analyses of prognostic factors. The selection of variables included in the proportional hazards regression analysis was according to the results of univariate and the clinical experiences. The factors included the age of onset, the gender of the patient, 
with/without EBV infection, the type of lymphomas (B or T/NK), the IPI scores, and weather the initial treatment contained etoposide. $\mathrm{P}<0.05$ was considered to denote a significant difference.

\section{Results}

\section{Patients Characteristics}

In the 66 patients, 39 were male, and 27 were female. The male to female ratio was 1.4:1. The median age of the patients was 48 years (15-76 years). Only two patients were under 16 years old, and both of them were 15 years old. As for the type of lymphoma, 32 patients were B cell lymphomas (29 B-cell non-Hodgkin lymphoma, 3 Hodgkin lymphoma) and the other 34 were T/NK cell lymphomas (18 NK/T cell lymphoma, 16 other T-cell non-Hodgkin lymphoma). 29 (43.9\%) patients were complicated with EBV infection. The patients" characteristics of the whole population was listed in Table 1.

\section{Treatment and outcome}

The baseline level between two group shows no differences $(p>0.05)$ (Table 1). The response rates of the 66 patients was $66.7 \%$ (44/66), with the CR rate of $24.2 \%$ (16/66) and PR rate of $42.4 \%(28 / 66)$. A total of 38 cases with initial etoposide achieved remission, and the remission rate was $73.1 \%$ (38/52), with the CR rate $28.8 \%$ (15/52) and PR 44.2\% (23/52). 6 cases used chemotherapy without etoposide achieved remission, and the remission rate was $42.9 \%(6 / 14)$, with the CR rate $7.1 \%(1 / 14)$ and PR rate $35.7 \%(5 / 14)$. A significant difference was noted between the two groups $(p=0.033)$. The level of myelosuppression shows no differences between two groups of patients $(p=0.122)$ (29 out of 52 cases in initial etoposide group and 9 out of 14 in no-initial etoposide group). In the 44 patients achieved CR/PR, there were 13 patients suffering HLH relapse (10 out of 38 cases in initial etoposide group and 3 out of 6 in no-initial etoposide group). 7 patients finally went through allo-HSCT.

A total of $40(60.6 \%)$ deaths occurred. Almost half of deaths occurred in the first 2 months $(42.5 \%, 17 / 40)$ and most of them occurred in the first 6 months after diagnosis $(77.5 \%, 31 / 40)$. There were $28(53.8 \%)$ deaths in patients with initial etoposide and 12 (85.7\%) deaths in the without-initial-etoposide group. For the cause of death, in the initial-etoposide group, there were 24 patients died of HLH progression $(85.7 \%$, 24/28), and 4 died of complications. In the without-initial-etoposide group, there were 11 patients died of HLH progression $(91.7 \%, 11 / 12)$, and 1 patient died during the conditioning before allo-HSCT.

\section{Survival}

The median survival of all patients is $23.8 \mathrm{w}$ [95\% $\mathrm{Cl}(15.5,32.2)]$. For the with-initial- etoposide group, the median survival time is $25.8 \mathrm{w}$ [ $95 \% \mathrm{Cl}(13.2,38.5)]$, and for the without-initial-etoposide group, is $7.8 \mathrm{w}$ [ $95 \%$ $(0,19.8)]$. The overall survival of the with-initial-etoposide group is significantly better than the other one $(p=0.048)$ (Figure 1). Considering almost half of patients died within 8 weeks ( 2 months), the overall survival at 2 months was estimated as $79.8 \% v s .46 .8 \%$, with a significant difference $(p=0.035)$. The treatment efficacy evaluation suggested that the overall survival was significantly prolonged in patients 
who reached CR/PR compared with patients who did not reached response $(\mathrm{p}<0.01)$ (Figure 2). Also, patients with positive EBV suffered a worse prognosis $(p=0.035)$ (Figure 3 ).

Multivariate cox analysis revealed that: for patients with EBV infection (29 cases), the type of lymphoma (B or T/NK cell) $(p=0.011)$ (Figure $4 a)$ and the IPI score $(p=0.004)$ was associated with prognosis (Figure $4 b)$, while whether etoposide was included in the initial treatment had no significant effect on prognosis $(P=0.474)$. However, in patients without EBV infection (37 cases), multivariate cox analysis showed that initial treatment with etoposide was significantly related to prognosis $(p=0.010, \operatorname{Exp}(B)=0.183)$, while the type of lymphoma $(p=0.259)$ and IPI score $(p=0.419)$ didn't show significantly effects (Figure 5) (Table 2).

\section{Discussion}

Malignancy HLH is one of the most common secondary HLH, especially in adult patients. M-HLH may occur in up to $1 \%$ of patients with hematologic malignancies, and the lymphoma associated HLH (LAHS) is the most common type in M-HLH[18]. M-HLH is considered to suffer the worst outcome among the secondary $\mathrm{HLH}[4,19]$. The mortality rate of $\mathrm{M}-\mathrm{HLH}$ is $>80 \%[4]$ and the median survival time is only 2 months $[5,6,19]$. However, there is currently no standard treatment strategy for LAHS. The priority of HLHdirected treatment and lymphoma-directed treatment is still controversial[5, 6, 13], even though in some clinical observation, many patients died of HLH within 2-4 weeks in spite of continued treatment of the underlying malignancy[6]. Etoposide is one of the core drugs in the HLH-94/2004 standard protocol, and its importance in the treatment and prognosis of HLH has been confirmed repeatedly [8, 9, 20]. But, its significance in LAHS's treatment has not yet been discussed. In the "How I treat" article in adult HLH, Alison S. and Nancy B. reported one case of LAHS patient who was effectively treated with etoposide combined with CHOP regimen[10]. In the 2017 adult M-HLH expert consensus review, it is recommended to prioritize treatment for cytokine storms and $\mathrm{T}$ cell proliferation, such as etoposide, for patients who have experienced severe organ damages[6]. In this study, it was evident that the early response rate, short-term survival, and overall survival of the treatment group containing etoposide were superior to those of lymphoma directed chemotherapy without etoposide.

The mechanism of etoposide in $\mathrm{HLH}$ is that it reduces the production of excessive proinflammatory factors by selectively ablating over-activated $T$ cells and inhibiting mononuclear-macrophage activation[21]. This effect is different from immunosuppressive effects of corticosteroids and the immunomodulatory effects of IVIG or cyclosporin, which makes it indispensable in some kind of HLH treatment strategy. Camille $B$ et al have an opinion that the long-term LAHS prognosis may be similar to the simple lymphoma not associated with $\mathrm{HLH}$, once the initial and crucial early period is overcome[11]. In our study, it was observed that nearly half of deaths occurred within 2 months after diagnosis. In addition to the early response rate, the improvement of 2-month survival rate was also significant in etoposidecontained group, and we believe that the improvement in short-term survival is also the reason etoposide group contributes to a better long-term survival. The underlining malignancy plays a crucial role in the development of HLH. Etoposide is a chemotherapy medication used for the treatment of a number of malignancies[22]. Although etoposide is not a commonly used first-line regimen in lymphoma, it has been 
reported that it can improve EFS and PFS in some patients with T-cell lymphoma under 60 years old[12, 23], also used in some B-cell lymphoma[24], indicating that the usage of etoposide in LAHS, not only effects on controlling $\mathrm{HLH}$, but also may effect on the underlining lymphoma.

For the intervention time of etoposide, considering the prognosis of LAHS patients who achieved early remission was significantly better, it is more appropriate to include etoposide in the initial treatment. However, the sever cytopenia caused by HLH may bring some concern for the usage of etoposide. One of the main reasons why less than $50 \%$ of LAHS patients received HLH directed treatment, is the concern of myelosuppression deterioration after cytotoxic therapy. But in fact, etoposide's efficiency occurs within 24$48 \mathrm{~h}$ and in $\mathrm{HLH}$, etoposide actually prevented the development of cytopenia and marrow hypocellularity in $\mathrm{HLH}$ instead[7, 20,25]. This study evaluated the level of myelosuppression and there was no significant difference between the two groups, but the dose of etoposide in this study was indeed adjusted according to adult intolerance and taking into account the cytopenia. It seems that as long as with appropriate doses, concerns about myelosuppression are not enough for holding etoposide back.

In the multivariate analysis, it was found that in patients with EBV infection, whether etoposide was included in the initial treatment had little effect on the prognosis, but in patients who did not suffer EBV infection, the initial treatment included etoposide could clearly improve the prognosis. In previous reports, whether it is T / NK-cell or B-cell lymphoma, the presence of EBV infection is often a poor prognostic factor[26, 27]. Also, as we all know, the type of lymphoma in LAHS is closely related with the prognosis. In the study of Sano $\mathrm{H}$ et al., the rate of early death was higher in patients with T/NK-cell LAHS than in those with B-cell LAHS (62.5 vs. 10.5\%)[28]. However, in this study, for patients without positive EBV, the type of lymphoma was not significantly correlated with prognosis. This result indicates that the poor prognosis of T/NK cell LAHS may be attributed to the fact that EB virus infection is more common in T/NK cell lymphoma. EBV infection itself is an independent prognostic factor. A possible conjecture is that when lymphoma is secondary to $\mathrm{HLH}$ and combined with positive EBV, EBV influences the prognosis from both aspects of lymphoma and HLH. In this EBV+ LAHS, the inclusion of etoposide in the initial treatment is not sufficient to improve the outcome. But for EBV- LAHS, initial treatment with etoposide is clearly helpful for prognosis.

\section{Conclusion}

As one of the most common secondary HLHs, LAHS suffers the worst outcome and most of patients died within a short term after diagnosis. However, no clear and unified initial treatment plan is currently available, and the debate about the priority of HLH-directed or lymphoma-directed is still going on. This study found that containing etoposide in the initial treatment plan significantly improve the early response rate, 2-month survival and overall survival, and especially prominent in EBV negative patients. Also, the level of bone marrow suppression shows no significant differences weather etoposide is contained. So, containing etoposide is suggested in the initial treatment of LAHS, weather using the HLH directed or lymphoma directed strategy, especially for EBV negative patients. 


\section{Abbreviations}

Allo-HSCT: Allogeneic hematopoietic stem cell transplantation; WBC: White blood cells; HGB hemoglobin; PLT: Platelets; LDH: lactate dehydrogenase; ALB: albumin; Cr: creatinine; TG: Triglycerides; ALT: Alanine aminotransferase; CR: Complete response; DEP regimen: Doxorubicin hydrochloride liposome, etoposide, and methylprednisolone; EBER: EBV encoded small RNA; EBV: Epstein-Barr virus; HLH: Hemophagocytic lymphohistiocytosis; L-DEP regimen: PEG-aspargase plus DEP regimen; NK: Natural killer; OS: Overall survival; PR: Partial response; VP-16: Etoposide;.

\section{Declarations}

\section{Ethics approval and consent to participate}

Ethical approval: All procedures performed in studies involving human participants were in accordance with the ethical standards of the institutional and/or national research committee and with the 1964 Helsinki declaration and its later amendments or comparable ethical standards. The study was approved by the Ethics Committee at Beijing Friendship Hospital.

Informed consent: Written informed consent was obtained from all individual participants or guardian for participants under 16 years old included in the study.

\section{Consent to publish}

\section{Availability of data and materials}

The datasets used during the current study are available from the corresponding author on request.

\section{Competing interests}

The authors declare that they have no competing Interest.

\section{Funding}

This work was supported by the National Natural Science Foundation of China (No.81871633); Beijing Natural Science Foundation (No.7181003); Beijing Municipal Administration of Hospitals' Ascent Plan (DFL20180101); Beijing Municipal Administration of Hospitals Incubating Program (PX2018003); Beijing Municipal Administration of Hospitals' Youth Program (QML20160102); and Beijing Municipal Administration of Hospitals Clinical Technology Innovation Project (XMLX201803). The funding body did not contribute to the design of the study and collection, analysis, and interpretation of data, or in writing the manuscript.

\section{Authors' contributions}

ZW contributed to the design of the study. YNW, JSW and LW helped with the study design and data analyses. YS conducted the data analysis and wrote the manuscript. All authors approved the final 
manuscript.

Acknowledgements

We thank the patients and their families for participating in our study.

\section{References}

1. Henter JI, Samuelsson-Horne A, Arico M, Egeler RM, Elinder G, Filipovich AH, Gadner H, Imashuku S, Komp D, Ladisch S et al: Treatment of hemophagocytic lymphohistiocytosis with HLH-94 immunochemotherapy and bone marrow transplantation. Blood 2002, 100(7):2367-2373.

2. Arico M, Janka G, Fischer A, Henter JI, Blanche S, Elinder G, Martinetti M, Rusca MP: Hemophagocytic lymphohistiocytosis. Report of 122 children from the International Registry. FHL Study Group of the Histiocyte Society. Leukemia 1996, 10(2):197-203.

3. Jordan MB, Allen CE, Weitzman S, Filipovich AH, McClain KL: How I treat hemophagocytic lymphohistiocytosis. Blood 2011, 118(15):4041-4052.

4. Otrock ZK, Eby CS: Clinical characteristics, prognostic factors, and outcomes of adult patients with hemophagocytic lymphohistiocytosis. American journal of hematology 2015, 90(3):220-224.

5. Tamamyan GN, Kantarjian HM, Ning J, Jain P, Sasaki K, McClain KL, Allen CE, Pierce SA, Cortes JE, Ravandi F et al: Malignancy-associated hemophagocytic lymphohistiocytosis in adults: Relation to hemophagocytosis, characteristics, and outcomes. Cancer 2016, 122(18):2857-2866.

6. Daver N, McClain K, Allen CE, Parikh SA, Otrock Z, Rojas-Hernandez C, Blechacz B, Wang S, Minkov M, Jordan MB et al: A consensus review on malignancy-associated hemophagocytic lymphohistiocytosis in adults. Cancer 2017, 123(17):3229-3240.

7. Henter JI, Horne A, Arico M, Egeler RM, Filipovich AH, Imashuku S, Ladisch S, McClain K, Webb D, Winiarski J et al: HLH-2004: Diagnostic and therapeutic guidelines for hemophagocytic lymphohistiocytosis. Pediatric blood \& cancer 2007, 48(2):124-131.

8. Song $Y, W a n g Y$, Wang $Z$ : Requirement for etoposide in the initial treatment of Epstein-Barr virusassociated haemophagocytic lymphohistiocytosis. British journal of haematology 2019, 186(5):717723.

9. Imashuku S, Kuriyama K, Teramura T, Ishii E, Kinugawa N, Kato M, Sako M, Hibi S: Requirement for etoposide in the treatment of Epstein-Barr virus-associated hemophagocytic lymphohistiocytosis. Journal of clinical oncology : official journal of the American Society of Clinical Oncology 2001, 19(10):2665-2673.

10. Schram AM, Berliner N: How I treat hemophagocytic lymphohistiocytosis in the adult patient. Blood 2015, 125(19):2908-2914.

11. Bigenwald C, Fardet L, Coppo P, Meignin V, Lazure T, Fabiani B, Kohn M, Oksenhendler E, Boutboul D, Uzzan $\mathrm{M}$ et al: A comprehensive analysis of Lymphoma-associated haemophagocytic syndrome in a large French multicentre cohort detects some clues to improve prognosis. British journal of haematology 2018, 183(1):68-75. 
12. Schmitz N, Trumper L, Ziepert M, Nickelsen M, Ho AD, Metzner B, Peter N, Loeffler M, Rosenwald A, Pfreundschuh M: Treatment and prognosis of mature T-cell and NK-cell lymphoma: an analysis of patients with T-cell lymphoma treated in studies of the German High-Grade Non-Hodgkin Lymphoma Study Group. Blood 2010, 116(18):3418-3425.

13. Lehmberg K, Sprekels B, Nichols KE, Woessmann W, Muller I, Suttorp M, Bernig T, Beutel K, Bode SF, Kentouche $\mathrm{K}$ et al: Malignancy-associated haemophagocytic lymphohistiocytosis in children and adolescents. British journal of haematology 2015, 170(4):539-549.

14. Collaborative Study to Evaluate the Proposed 1st WHO International.

15. Wang Y, Huang W, Hu L, Cen X, Li L, Wang J, Shen J, Wei N, Wang Z: Multicenter study of combination DEP regimen as a salvage therapy for adult refractory hemophagocytic lymphohistiocytosis. Blood 2015, 126(19):2186-2192.

16. Marsh RA, Allen CE, McClain KL, Weinstein JL, Kanter J, Skiles J, Lee ND, Khan SP, Lawrence J, Mo JQ et al: Salvage therapy of refractory hemophagocytic lymphohistiocytosis with alemtuzumab. Pediatric blood \& cancer 2013, 60(1):101-109.

17. World Health Organisation. The WHO Toxicity Grading Scale for Determining the Severity of Adverse Events. 2003. Available from URL: http://wwwicsscorg/Documents/Resources/AEManual2003AppendicesFebruary_06_2003\%20finalpdt (Accessed 22 Mar 2015).

18. Machaczka M, Vaktnas J, Klimkowska M, Hagglund H: Malignancy-associated hemophagocytic lymphohistiocytosis in adults: a retrospective population-based analysis from a single center. Leukemia \& lymphoma 2011, 52(4):613-619.

19. Parikh SA, Kapoor P, Letendre L, Kumar S, Wolanskyj AP: Prognostic factors and outcomes of adults with hemophagocytic lymphohistiocytosis. Mayo Clinic proceedings 2014, 89(4):484-492.

20. Arca M, Fardet L, Galicier L, Riviere S, Marzac C, Aumont C, Lambotte O, Coppo P: Prognostic factors of early death in a cohort of 162 adult haemophagocytic syndrome: impact of triggering disease and early treatment with etoposide. British journal of haematology 2015, 168(1):63-68.

21. Johnson TS, Terrell CE, Millen SH, Katz JD, Hildeman DA, Jordan MB: Etoposide selectively ablates activated $\mathrm{T}$ cells to control the immunoregulatory disorder hemophagocytic lymphohistiocytosis. Journal of immunology 2014, 192(1):84-91.

22. Pommier $\mathrm{Y}$, Leo $\mathrm{E}$, Zhang $\mathrm{H}$, Marchand $\mathrm{C}$ : DNA topoisomerases and their poisoning by anticancer and antibacterial drugs. Chemistry \& biology 2010, 17(5):421-433.

23. Ellin $F$, Landstrom J, Jerkeman $M$, Relander $T$ : Real-world data on prognostic factors and treatment in peripheral T-cell lymphomas: a study from the Swedish Lymphoma Registry. Blood 2014, 124(10):1570-1577.

24. Dodero A, Guidetti A, Tucci A, Barretta F, Novo M, Devizzi L, Re A, Passi A, Pellegrinelli A, Pruneri G et al: Dose-adjusted EPOCH plus rituximab improves the clinical outcome of young patients affected by double expressor diffuse large B-cell lymphoma. Leukemia 2019, 33(4):1047-1051. 
25. Mizrahi M, Ben-Chetrit E: Relapsing macrophage activating syndrome in a 15-year-old girl with Still's disease: a case report. Journal of medical case reports 2009, 3:138.

26. Fei Q, Tian XK, Wu J, Zhu HM, Wang Y, Peng FY, Zhang WJ, Yin L, He X: Prognostic significance of Epstein-Barr virus DNA in NK/T-cell lymphoma: a meta-analysis. OncoTargets and therapy 2018, 11:997-1004.

27. Castillo JJ, Beltran BE, Miranda RN, Young KH, Chavez JC, Sotomayor EM: EBV-positive diffuse large B-cell lymphoma of the elderly: 2016 update on diagnosis, risk-stratification, and management. American journal of hematology 2016, 91(5):529-537.

28. Sano H, Kobayashi R, Tanaka J, Hashino S, Ota S, Torimoto Y, Kakinoki Y, Yamamoto S, Kurosawa M, Hatakeyama $\mathrm{N}$ et al: Risk factor analysis of non-Hodgkin lymphoma-associated haemophagocytic syndromes: a multicentre study. British journal of haematology 2014, 165(6):786-792.

\section{Tables}

Table 1 Initial clinical characteristics of the patients between 2 groups. 


\begin{tabular}{|c|c|c|c|c|}
\hline Clinical features & With initial etoposide & $\begin{array}{l}\text { Without initial } \\
\text { etoposide }\end{array}$ & $\begin{array}{l}\mathrm{p} \\
\text { valve }\end{array}$ & Total \\
\hline & $(n=52)$ & $(n=14)$ & & $(n=66)$ \\
\hline \multicolumn{5}{|l|}{ Age, years } \\
\hline Median & 48 & 44.5 & 0.881 & 48 \\
\hline Range & {$[15,76]$} & {$[29,65]$} & & {$[15,76]$} \\
\hline Gender & & & 0.544 & \\
\hline Male (n) & 32 & 7 & & 39 \\
\hline Female (n) & 20 & 7 & & 27 \\
\hline $\begin{array}{l}\text { Lymphoma } \\
\text { classification }\end{array}$ & & & 0.635 & \\
\hline B cell & 26 & 6 & & 32 \\
\hline $\mathrm{T} / \mathrm{NK}$ cell & 26 & 8 & & 34 \\
\hline Fever $\left(\mathrm{T}>38.5^{\circ} \mathrm{C}\right)$ & $52(100 \%)$ & $14(100 \%)$ & & $66(100 \%)$ \\
\hline Splenomegaly (n) & $38(73.1 \%)$ & $11(78.6 \%)$ & 1.00 & $49(74.2 \%)$ \\
\hline $\begin{array}{l}\text { Haemophagocytosis } \\
\text { (n) }\end{array}$ & 45 (86.5\%) & $11(78.6 \%)$ & 0.431 & $56(84.8 \%)$ \\
\hline WBC $\left(* 10^{9} / \mathrm{L}\right)$ & $2.25[0.06,17.00]$ & $3.25[0.4,8.75]$ & 0.165 & $2.55[0.06,17.00]$ \\
\hline $\operatorname{HGB}(\mathrm{g} / \mathrm{L})$ & $90.05 \pm 21.84$ & $81.71 \pm 15.11$ & 0.184 & $88.29 \pm 20.781$ \\
\hline $\operatorname{PLT}\left({ }^{*} 10^{9} / \mathrm{L}\right)$ & $47.5[3,344]$ & $61.5[9,392]$ & 0.252 & $50.5[3,392]$ \\
\hline $\mathrm{ALT}(\mathrm{U} / \mathrm{L})$ & $52.5[7.0,798.0]$ & $41.5[13,235]$ & 0.753 & $51.5[7.0,798.0]$ \\
\hline AST (U/L) & $56.4[3.3,520.2]$ & $43.9[14.3,990.0]$ & 0.869 & $55.2[3.3,990.0]$ \\
\hline LDH & $556[137,4581]$ & $990[76,1986]$ & 0.569 & $537[76,4581]$ \\
\hline $\begin{array}{l}\text { Total bilirubin } \\
(\mu \mathrm{mol} / \mathrm{L})\end{array}$ & $24.77[6.29,348.15]$ & $20.70[6.50,213.58]$ & 0.718 & $22.9[6.29,348.15]$ \\
\hline ALB & $28.5[19.2,44.0]$ & $28.7[20.1,34.8]$ & 0.389 & $28.2 \pm 5.27$ \\
\hline $\mathrm{Cr}$ (umol/L) & $59.7[35.5,125]$ & $64.4[37.7,272.3]$ & 0.725 & $60[35.5,272.3]$ \\
\hline TG (mmol/L) & $2.45 \pm 1.22$ & $2.95 \pm 1.49$ & 0.215 & $2.30[0.69,5.68]$ \\
\hline $\mathrm{Fbg}(\mathrm{g} / \mathrm{L})$ & $1.76[0.16,8.47]$ & $3.7[0.73,8.68]$ & 0.017 & $1.96[0.16,8.68]$ \\
\hline Ferritin (ng/mL) & $\begin{array}{l}2307.5[204.3 \\
75000]\end{array}$ & $2574[557.3,45487]$ & 0.734 & $2447[204.3,75000]$ \\
\hline $\mathrm{sCD} 25(\mathrm{pg} / \mathrm{mL})$ & $36605[661,44000]$ & $34749[3827$, & 0.903 & $36517[661,44000]$ \\
\hline
\end{tabular}


44000]

\begin{tabular}{|lllll|}
\hline IPI scores & $3.00 \pm 0.913$ & $3.29 \pm 0.994$ & 0.315 & $3.06 \pm 0.931$ \\
\hline EBV-positive & $23(44.2 \%)$ & $6(42.8 \%)$ & 0.927 & $29(43.9 \%)$ \\
\hline Outcome & & & \\
\hline Death & $28(53.8 \%)$ & $12(85.7 \%)$ & 0.030 & $40(60.6 \%)$ \\
Survival & $25.8 \mathrm{w}[95 \% \mathrm{Cl}(13.2$, & $7.6 \mathrm{w}[95 \%(0,19.8)]$ & 0.048 & $23.8 \mathrm{w}[95 \% \mathrm{Cl}(15.5$, \\
& $38.5)]$ & & $32.2)]$ \\
\hline
\end{tabular}

the valve was expressed as median [range] or mean \pm standard deviation.

Table 2. Univariable and multivariable analyses of prognosis with different factors

\begin{tabular}{|lllll|}
\hline Variables & Univariate Analysis & \multicolumn{3}{l|}{ Multivariate Analysis } \\
\cline { 3 - 5 } & & Exp(B) & $95 \% \mathrm{Cl}$ & p valve \\
\hline Age & 0.981 & 1.008 & $0.979-1.037$ & 0.614 \\
\hline Gender (male vs. female) & 0.810 & 0.729 & $0.370-1.438$ & 0.362 \\
\hline EBV infection (with vs. without) & 0.002 & 2.272 & $1.060-4.867$ & 0.035 \\
\hline Lymphoma classification (T/NK vs. B) & 0.010 & 2.898 & $1.167-7.197$ & 0.022 \\
\hline IPI score & 0.107 & 1.459 & $1.032-2.165$ & 0.033 \\
\hline Treatment (initial etoposide vs. without) & 0.048 & 0.682 & $0.324-1.433$ & 0.312 \\
\hline
\end{tabular}

\section{Figures}




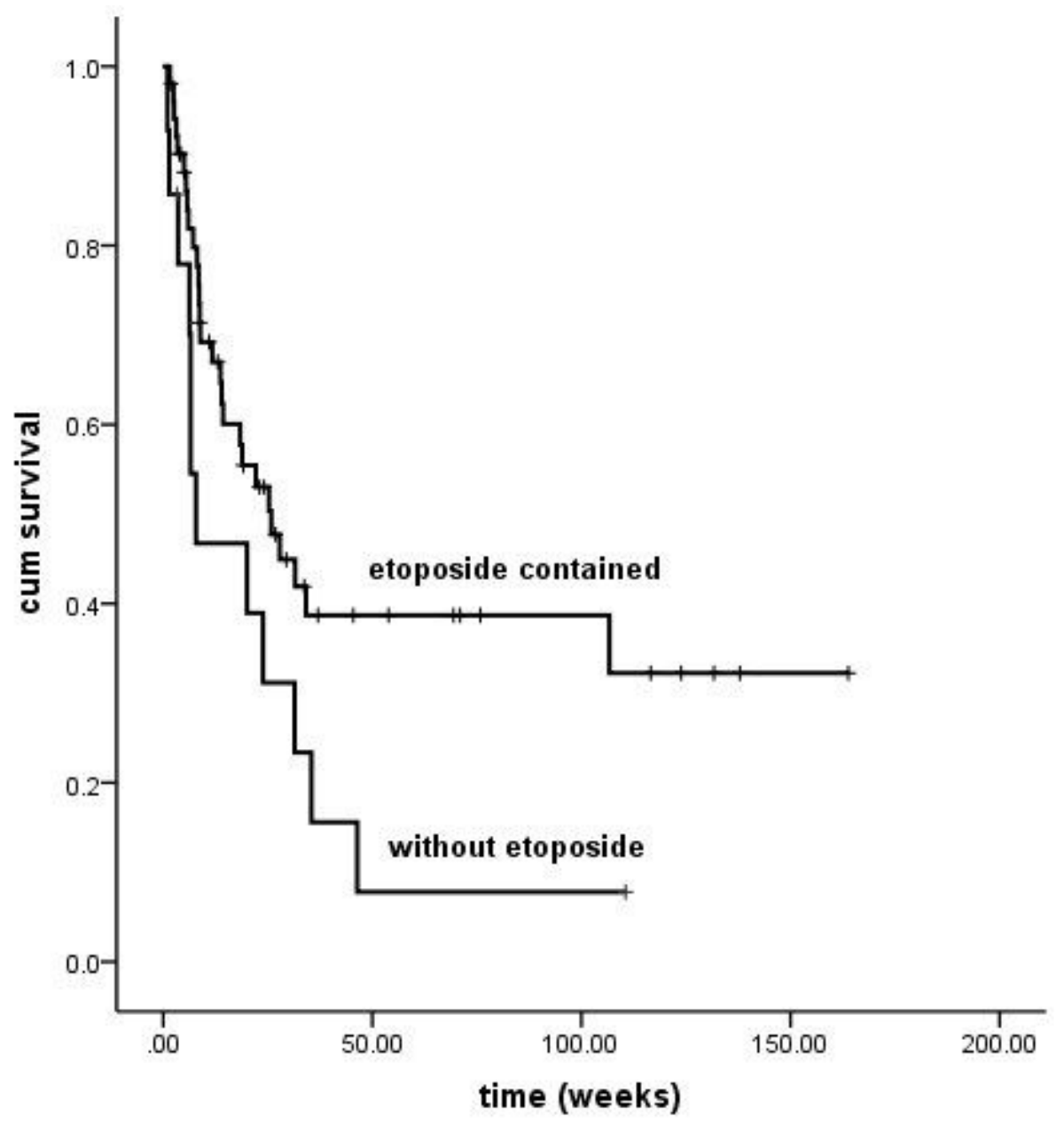

\section{Figure 1}

Etoposide contained in initial treatment significantly improve the prognosis of LAHS, comparing with the only lymphoma directed therapy one $(p=0.048)$. 


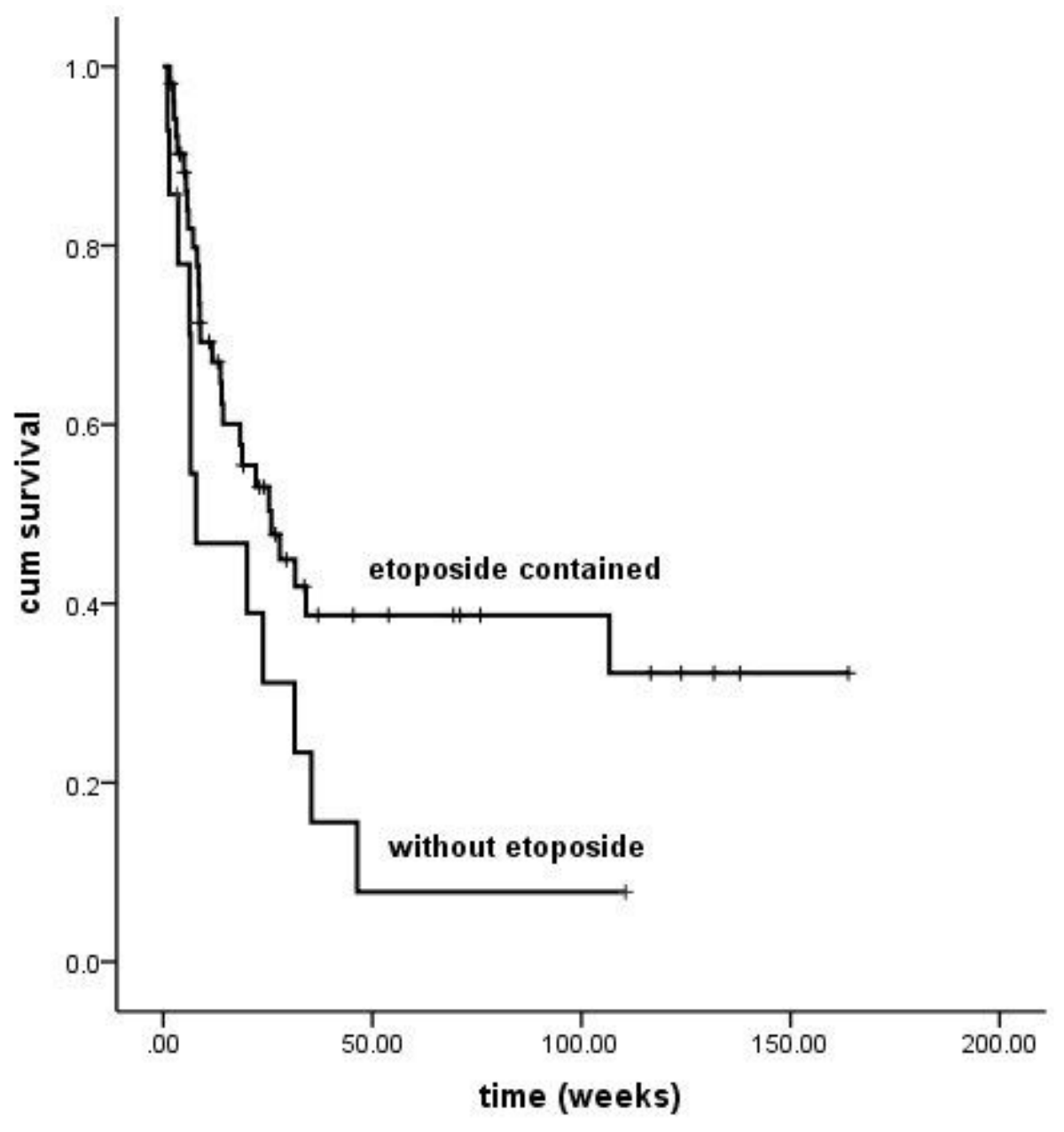

\section{Figure 1}

Etoposide contained in initial treatment significantly improve the prognosis of LAHS, comparing with the only lymphoma directed therapy one $(p=0.048)$. 


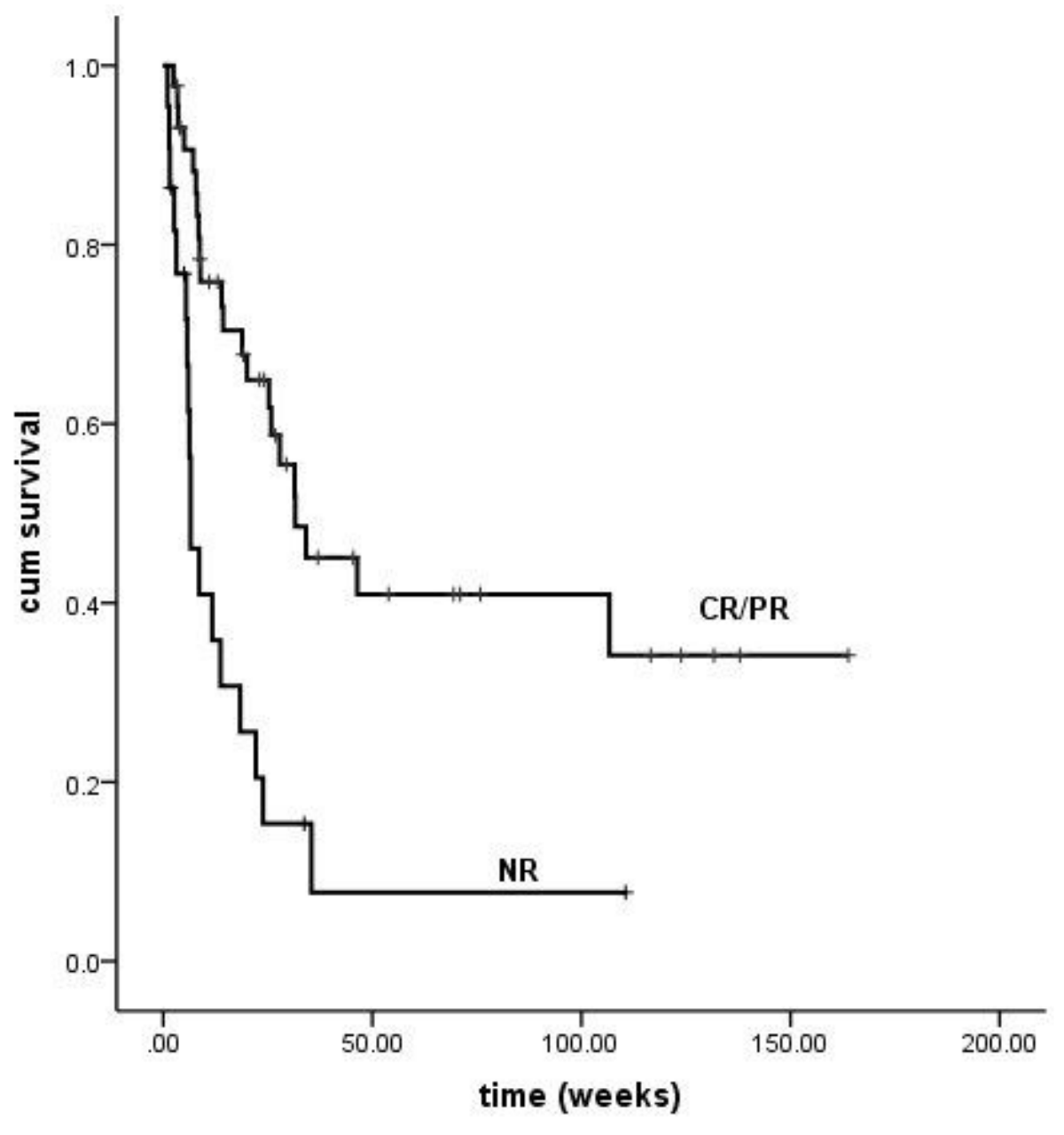

Figure 2

The treatment efficacy evaluation suggested that the overall survival was significantly prolonged in patients who reached CR/PR compared with patients who did not reached response $(p<0.01)$. 


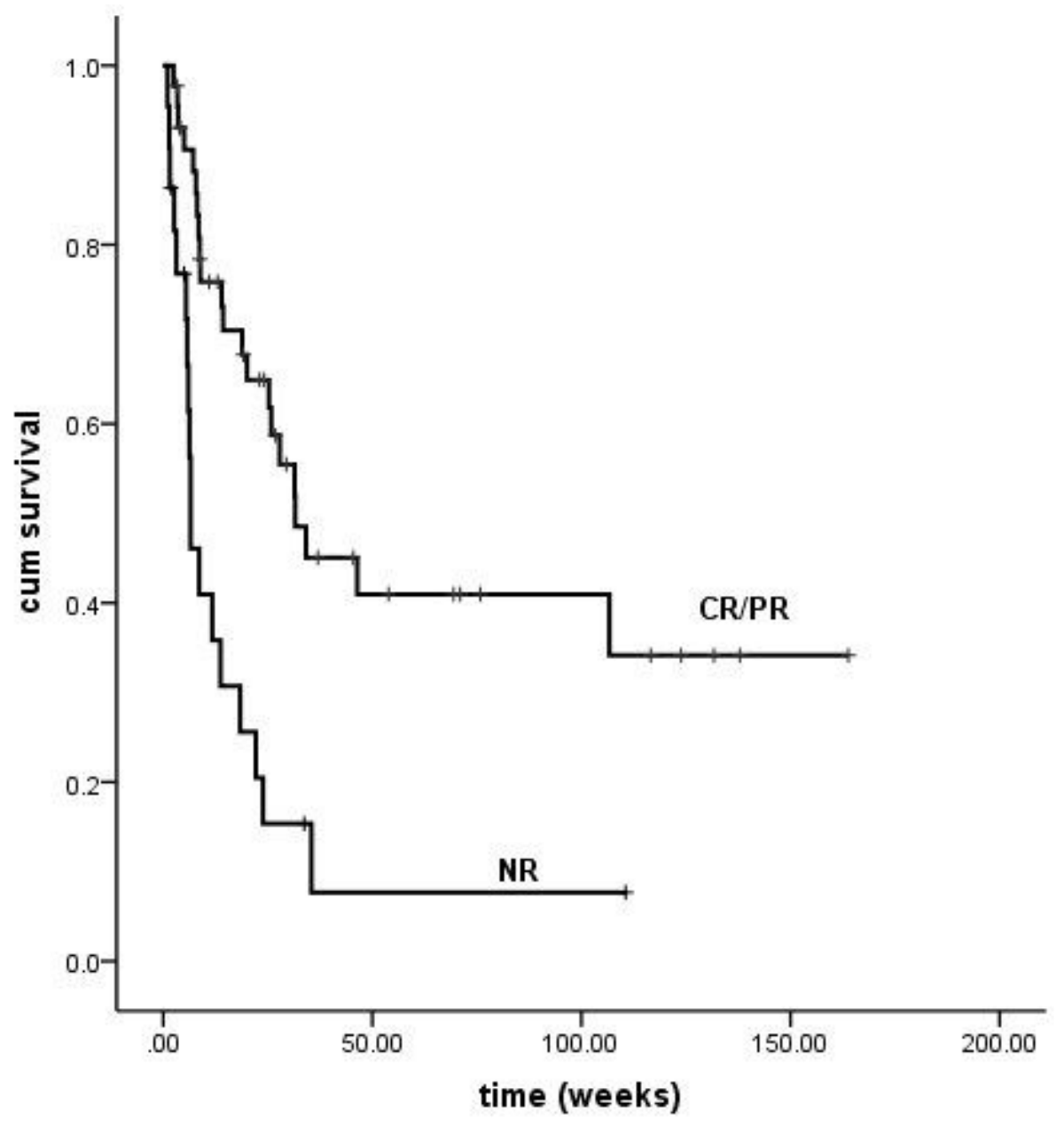

Figure 2

The treatment efficacy evaluation suggested that the overall survival was significantly prolonged in patients who reached CR/PR compared with patients who did not reached response $(p<0.01)$. 


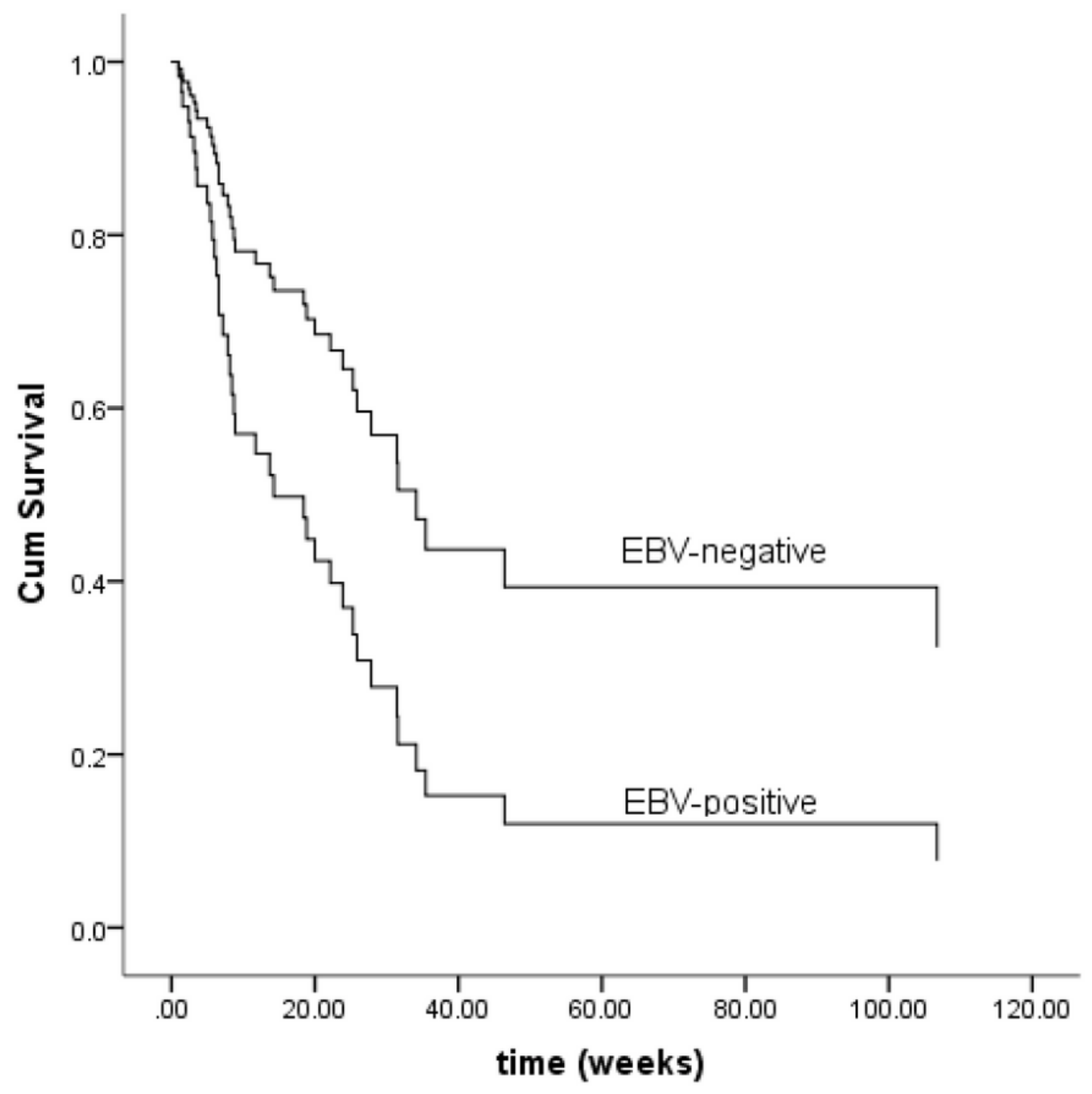

Figure 3

Adjusted survival curves of patients with or without EBV infection. Patients with positive EBV suffered a worse prognosis $(\mathrm{p}=0.035)$. 


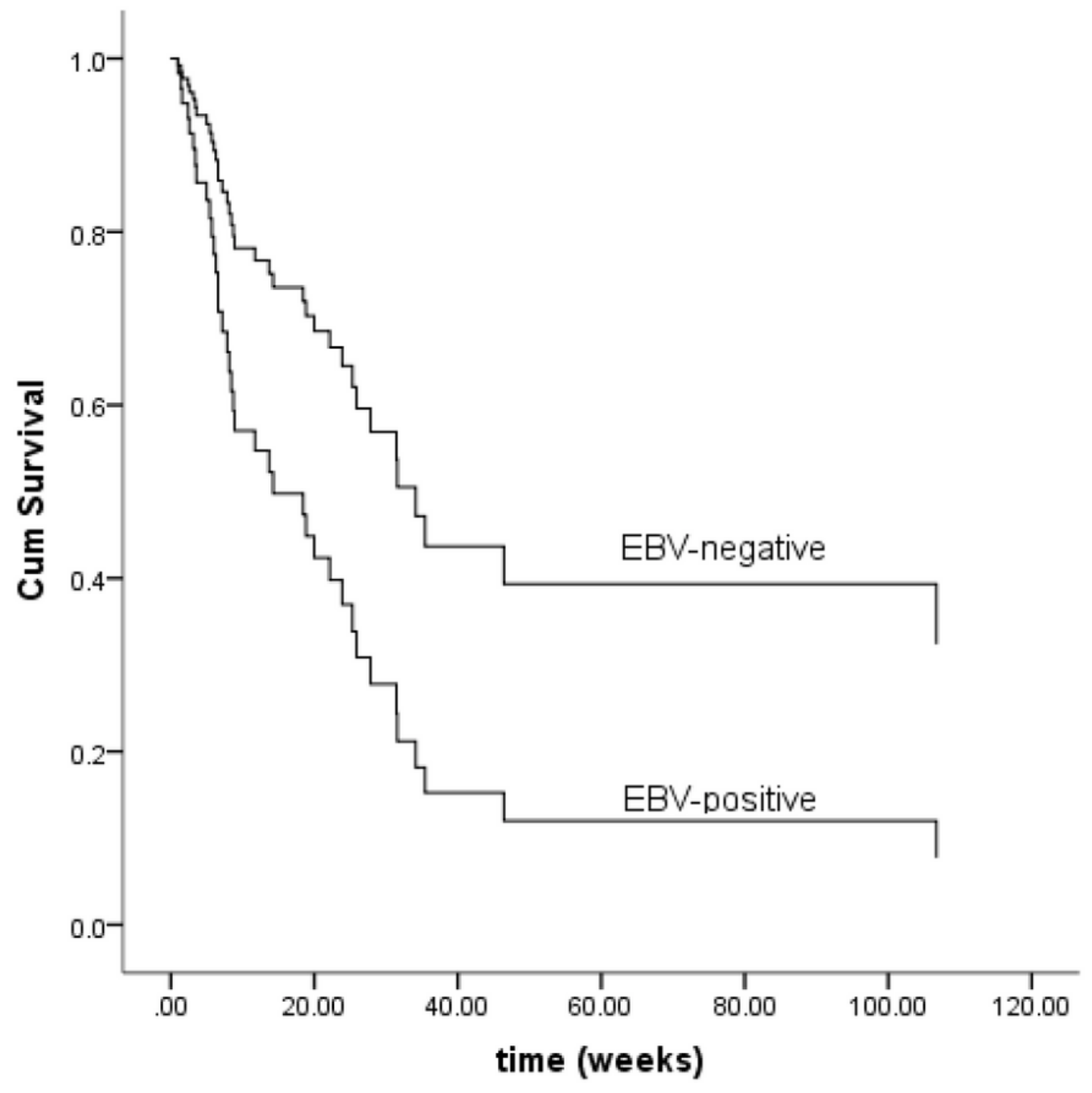

Figure 3

Adjusted survival curves of patients with or without EBV infection. Patients with positive EBV suffered a worse prognosis $(\mathrm{p}=0.035)$. 

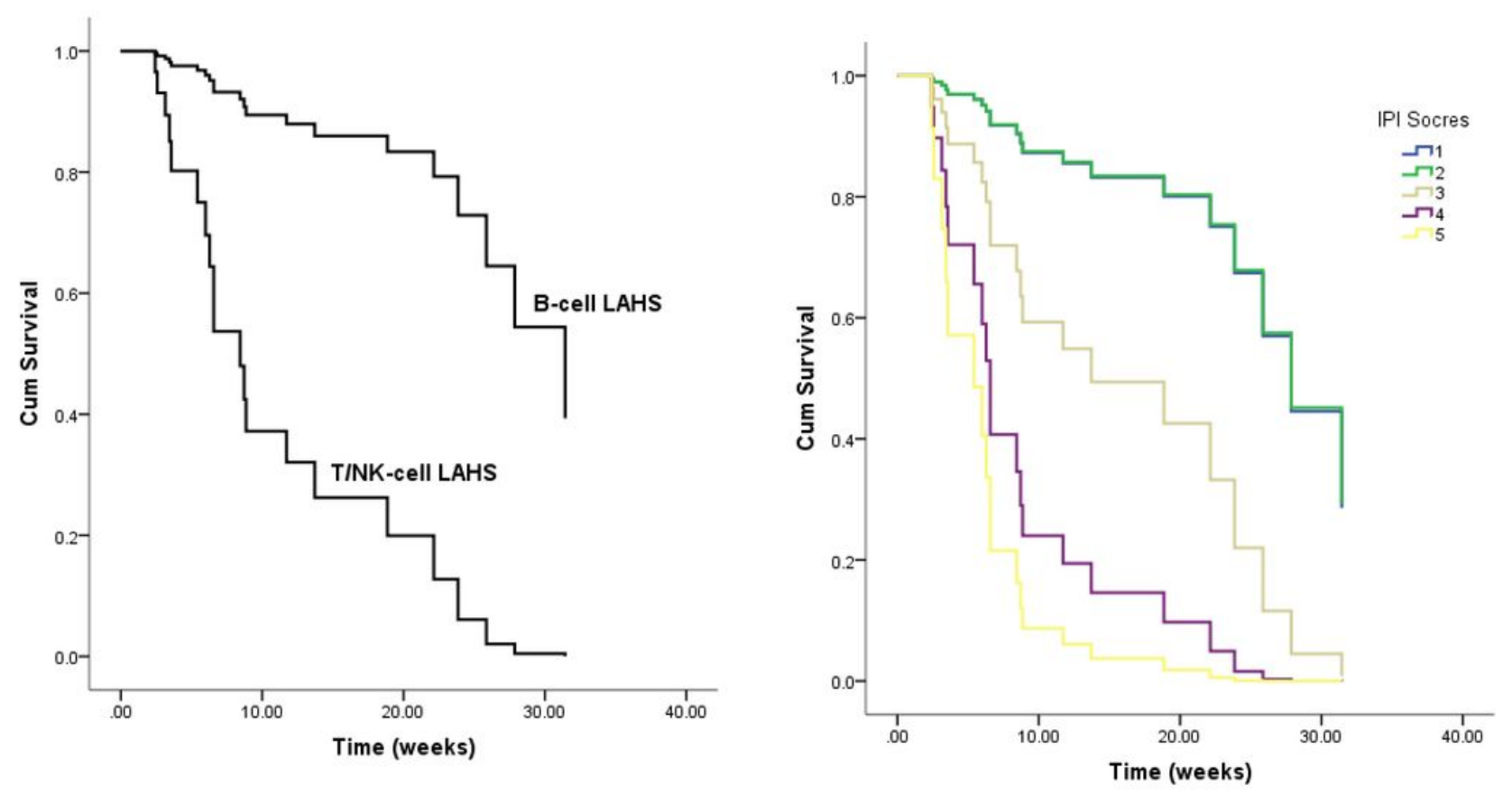

Figure 4

For EBV-positive patients, COX analysis: age of onset, the gender of the patient, the type of lymphomas (B or T/NK), the IPI scores of lymphomas, and weather the initial treatment contained etoposide, the results showed type of lymphoma (Figure $4 a)(P=0.011, \operatorname{ExpB}=0.113)$ and the IPI socores (Figure $4 b)(p=0.004$, $\operatorname{ExpB}=2.419)$ was associated with prognosis.
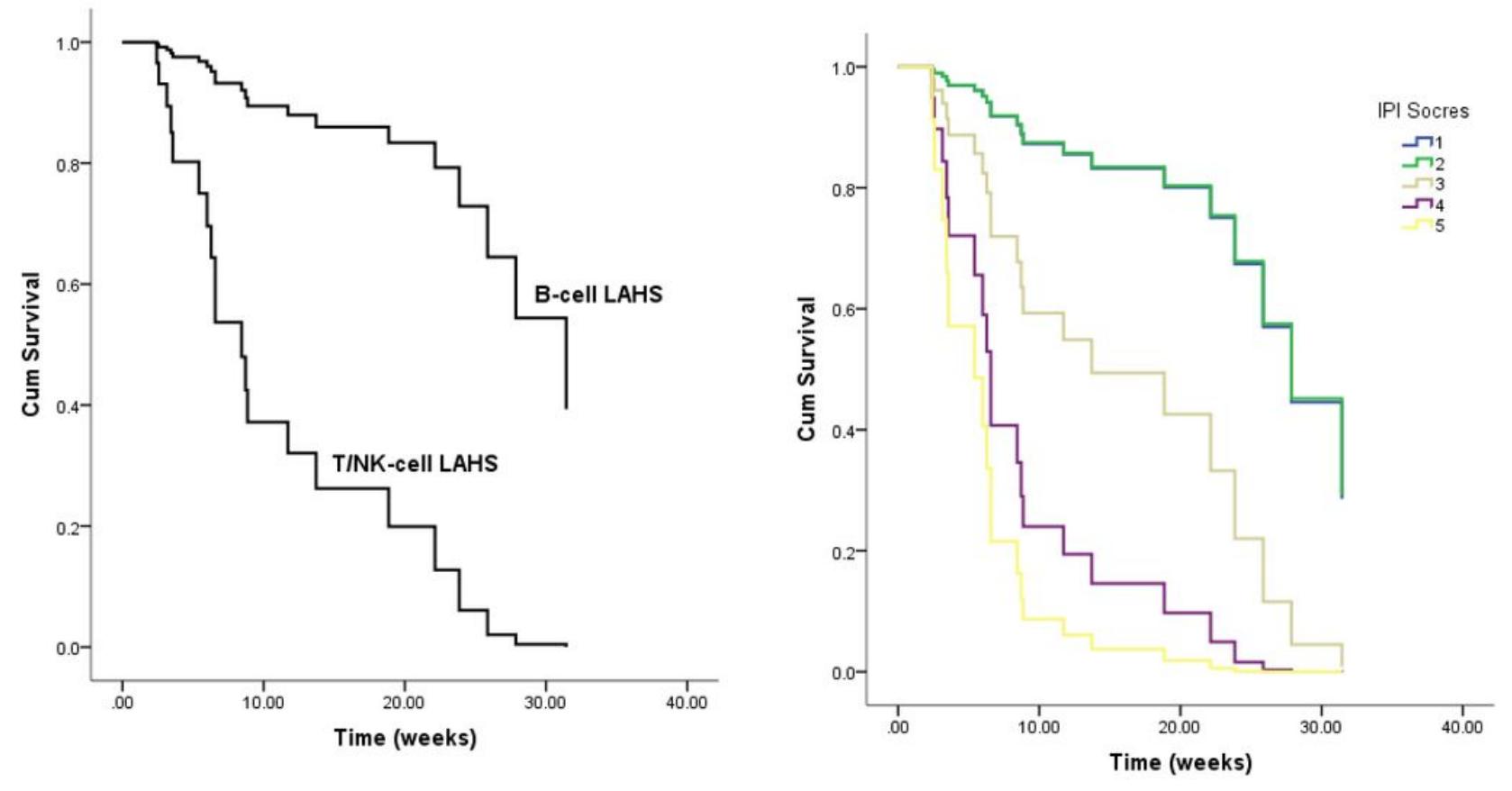

Figure 4

For EBV-positive patients, COX analysis: age of onset, the gender of the patient, the type of lymphomas (B or T/NK), the IPI scores of lymphomas, and weather the initial treatment contained etoposide, the results 
showed type of lymphoma (Figure 4a) $(P=0.011, E x p B=0.113)$ and the IPI socores (Figure 4b) $(p=0.004$, $\operatorname{ExpB}=2.419)$ was associated with prognosis.

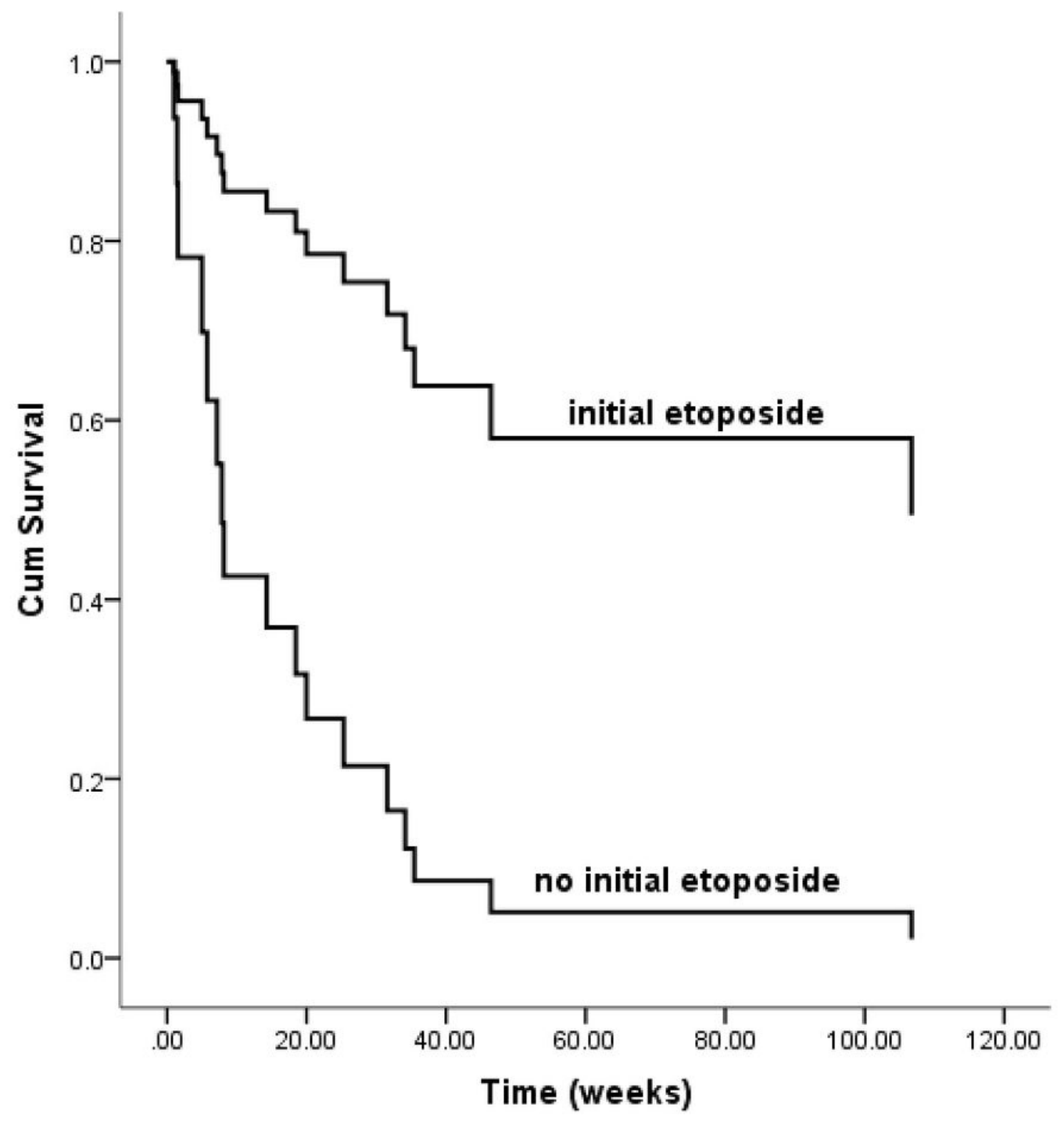

Figure 5

For EBV-negative patients, COX analysis: age of onset, the gender of the patient, the type of lymphomas (B or T/NK), the IPI scores of lymphomas, and weather the initial treatment contained etoposide, the results showed that weather initial treatment contained etoposide $(p=0.010, \operatorname{Exp} B=0.183)$ was associated with prognosis. 


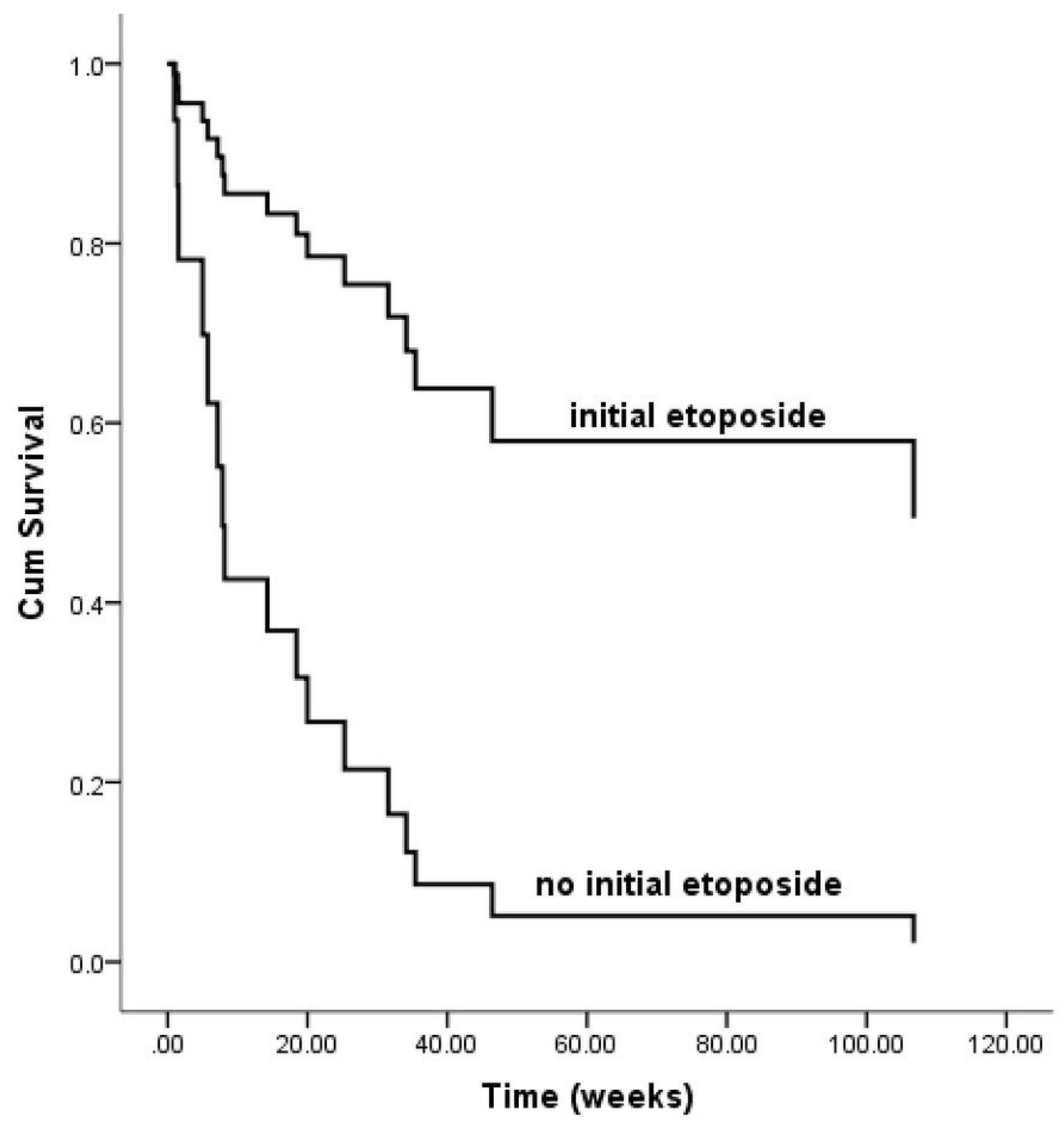

Figure 5

For EBV-negative patients, COX analysis: age of onset, the gender of the patient, the type of lymphomas (B or T/NK), the IPI scores of lymphomas, and weather the initial treatment contained etoposide, the results showed that weather initial treatment contained etoposide $(p=0.010, \operatorname{Exp} B=0.183)$ was associated with prognosis. 